Proceedings of the Creative Construction Conference (2018)

Edited by: Miroslaw J. Skibniewski \& Miklos Hajdu

DOI 10.3311/CCC2018-070

Creative Construction Conference 2018, CCC 2018, 30 June - 3 July 2018, Ljubljana, Slovenia

\title{
Identifying factors of risk management for the construction industry
}

\author{
Berenger Yembi Renault ${ }^{\mathrm{a} *}$ and Nazeem Ansary ${ }^{\mathrm{b}}$ \\ ${ }^{a^{*}, a \& b}$ Dept of Construction Management \& Quantity Surveying, University of Johannesburg, Cnr Siemert \& Beit Streets, Doornfontein, 2028, \\ Johannesburg, South Africa
}

\begin{abstract}
Delays and cost overruns are recurrent in construction projects. Risk management (RM) has been developed to curtain risks associated with construction projects. However, there is no consensus of what factors should constitute RM for construction projects. Therefore, this paper scrutinises preceding studies on the theme of RM and establish core risk management factors (RMFs) that are indispensable to make the concept valuable in the construction industry (CI). A literature search related to RM was conducted in order to identify common RMF. It was indicated that there is still misunderstanding and disagreement over the factors that should constitute RM in construction. However, the RMFs of organisational environment, defining objectives, resource requirement, risk measurement, risk identification, risk assessment, risk response and action planning, communication, monitoring, review and continuous improvement dominate the literature. Identifying RMF that can effortlessly be understood and implemented will contribute to ameliorating the current RM status and boosting the body of knowledge.
\end{abstract}

(C) 2018 The Authors. Published by Diamond Congress Ltd., Budapest University of Technology and Economics Peer-review under responsibility of the scientific committee of the Creative Construction Conference 2018.

Keywords: Contraction; factors;model; risk management effectiveness

\section{Introduction}

The construction industry (CI) is one of the largest employers globally. A report released by the Organization for Economic Co-operation and Development [1] indicated that the CI employs approximately $7 \%$ of the global work force or 180 million people and it is predicted to account for approximately $13 \%$ of the Global Domestic Product (GDP) by 2020. The CI is visibly a significant sector of most economies including. Because of the industry's economic significance, and the need to ameliorate the image of the CI tarnished by the high rate of project failure, many organizations have focused on RM effectiveness in the CI. References [2]; [3] supported this statement by indicating that RM improvement in construction has lately become a precedence and as a result has attracted industry-wide attention. However, improving RM effectiveness in the CI has also proved to be somewhat challenging partially owing to the industry's multifaceted nature. Regardless of the multifaceted nature of the industry, RM effectiveness improvement remains a critical concern and its importance has been illustrated in several studies [3]; [4]; [5]; [6];. The need for improving the performance of RM in the $\mathrm{CI}$ has been acknowledged and thus numerous ways of improving RM performance have been proposed. Among these proposals are continual improvement of RM systems [7], commitment of the board and senior management [8]; [9], share understanding and approach to RM across department (Beasley et al., 2010), use of RM techniques and tools [10], and have a RM information system [12]; [9].

However, RM and principally the uncertainty around factors of RM have been identified as being the reason of lack of RM implementation among construction firms and consequently the leading reason for delays and cost overruns observed in construction projects [13]; [14]; [15]; [16]. There is also a common consent on the fact that RMFs can influence or have an impact on construction project outcome [17]; [18]; [19]. However there is no unanimity on the factors that should constitute RM and how useful these factors can be in order to improve RM and consequently project

Corresponding author: renault08@yahoo.fr 
performance. A review of literature indicated dissimilar definitions [20]; [21]; [22]; [23]. Consequently, it may be inferred that the disagreement on these issues could have been the reason partly for not using comprehensively the concept to improve RM performance in the CI.

A review of recent literature on the theme of RM was conducted and as a consequence, it was deduced that RM can be measured and used as a performance indicator. Factors of RM have also been identified in order to operationalize in a practical and useful way the concept of RM.

\section{Literature review}

\section{Risk management status of the South African construction industry}

Regardless of the initiatives deployed by the SA government to improve project management and quality performance, project overruns continue to occur in SA [24]; for example, the Gautrain project which was only ready two years after its baseline completion date and cost R14 billion over budget [25]. A further example is an R2.5 billion contract for a multi-product pipeline between Durban and Gauteng for Transnet was estimated to cost R23.4 billion and the completion date was almost 3 years late [26]. The continuing ineffective project RM of the CI in the form of cost and time overruns, poor quality achievement, project not meeting technical requirement, project not achieving user/client satisfaction, provided the catalyst for a new approach to RM in the form of consolidated construction RM and regulatory compliance legislation such as the Construction Regulations of 2003. This legislative framework required new multi-stakeholder interventions [27]. However, reference [28] indicated that there was a very little commitment to conforming to basic requirements, let alone promoting a culture of RM. Contractors could hardly maintain their RM tools and equipment and regarded RMI as costly activities. Improvement of the standard of RM performance of construction SMEs could inevitably be helped by continuous monitoring and review of their RM performance. Furthermore, reference [29] postulated that in SA, RM was also not widely used in the engineering and construction environment, and there was lack of actual adoption and implementation of RM practices. In order to overcome project failures [30] established that project success is highly dependent upon the implementation of RM practices. Reference [31] described it as one of the most capable areas and critical procedures that help to complete projects successfully. Additionally, reference [32] stated that the implementation of RM is closely aligned with overall project performance. Despite of the noted benefits of RM, cost and time overruns poor quality of work and, clients not satisfied, continue to occur on construction projects. The poor project performance highlight the need to determine RM practices those construction enterprises can use to improve their project performance. Furthermore, the plethora of studies lack consensus of the RM practices to be used by construction enterprises to improve their project performance.

\section{Why risk management?}

The reason RM is worth considering or pursuing for project performance improvement, is improved RM effectiveness has been attributed to an improvement in the RM culture of organisations in many studies including that of [3]; [4]; [5]; [33]. A better project performance has been associated with a positive RM culture dominating within an organisation concerned and indeed the industry [34]; [35]. The prevailing culture is thus very important in so far as the enhancement of construction project performance is concerned. It is because of this observation that [6] rightly argue that it seems that attempts to improve the project failures' record will not be fully realised until the RM culture is enhanced.

Consequently, it not astonishing that an effective RM is acknowledged to be a critical element of attaining and maintaining satisfactory standards of project performance [3]. It is also for this reason that reference [1] contends that it is not enough for instance to provide safe equipment, systems and procedures if the culture is not conducive to healthy and safe working. Most project failures in construction attest to the foregoing. For example "ineffective risk management" was identified as a factor leading to poor project performance by reference [36]; [37]; [38] and recently, a study conducted by reference [24] mentioned relational risk management (RRM) as one of the leading reason of project failure in construction as they argued that construction projects are usually 'people' intensive hence human nature, cultures and personalities are key variables to consider when discussing construction risk. RRM is embedded in formal and informal communication channels in the project where the cultures' of the participating organisations plays an integral role [39]. This statement is supported by reference [40] who indicated that sharing of mutual objectives, adopting a no-blame culture and aiming for continuous improvement will result in increased project success. To illustrate how other industries regard RRM, reference [39] observed that the High Reliability Organisations (HRO's) such as the Oil and Gas, Air traffic control system, naval aircraft carriers and Nuclear power operations, where serious hazards are constantly present, operating organisations and their regulators pay considerable attention 
to risk assessment and management. They noted that these assessments are mainly on leading indicators focusing on safety climate which is a measure or determinant of the prevailing culture, because as stated earlier most of these industries have realised the importance of risk management for better project handling [3].

Furthermore, risk management at organisation level influences the deployment and effectiveness of the risk management resources, policies, practices and procedures [41]. Traditionally, attempts to improve workplace risk management concentrated on technical issues and individual human failures. However, from investigations that have been conducted in the past, the importance of risk management has been highlighted. For example, reference [42] on the investigation into the situation of British Petroleum (BP) Oil Spill in Gulf of Mexico, stated that a change in the way management approaches unpredicted events was required throughout the organisation and also at project level. Likewise, reference [43] study concluded on the Millennium Dome in south East London that it is essential to create an atmosphere in which approach and understanding of risk management is shared as the number one priority.

It has become obvious that organisations' exposure to uncertainty and risk does not merely stem from 'human errors', chance, environmental factors or technological failures alone. Rather, it is the ingrained organisational policies and standards which have constantly been shown to be at the centre of the catastrophe [1]. It is the prevailing culture in an organisation and that is the reason why RM has become important.

\section{What is risk management?}

RM denotes a coordinated set of activities and procedures that is employed to direct an organisation and to control possible events that may prevent projects from achieving established objectives [44]. RM is further defined in ISO 31000 as the identification, assessment, and prioritization of risks followed by coordinated and economical application of resources to reduce, monitor, and control the possibility and/or impact of unfortunate events [45]. RM, therefore, informs project team members on how they could manage risk, what resources are required and the cost to manage these risks [27]; [5]. This definition is also summed up by 'the way organisations anticipate on potential threats to projects' [6]; [46]; [4].

It is essential to note that there is always some form of procedure that an organisation follows to protect itself against unwanted events. The only thing is that the RM approach and methods employed to manage risks may vary among organisations. Reference [41] indicated that organisational RM exists on a continuum and that organisations can either have a good or poor RM performance. Project RM can also be referred to as the subset of an organisation's enterprise RM plan [47]; [48]. Reference [49] opined to that the necessity to manage risk in construction is continuously growing owing to various reasons which include but not limited to the intricacy, competition, size, politico-economic challenge, client-consumer requirements. Hence, the operationalization of RM in the CI cannot be overlooked. However, for RM to be operationalized, it is pivotal to know what influence it.

\section{Factors of risk management}

Confusion has reigned around what should constitute RM, partially owing to the multitude of terms that have been employed to designate the activities undertaken under RM. Some studies have referred to the parts which form, shape or make up risk management as indicators [50]; [51], factors [22]; [20]; [21]; [52]; [23], elements [53]; 54]; [6] and attributes [55]; [56] of enhanced risk management. Thus, it is important to know what these terms mean to lessen partially the confusion. The Cambridge Advanced Learner's Dictionary [57] defines the identified terms as follows:

- Indicator (noun): something that shows what a situation is like.

- Factor (noun): A fact or situation which influences the result of something.

- Element (noun): A part of something, it can be referred to as what makes up something.

- Attribute(s) (noun): A quality or characteristic that someone or something has.

An examination of the above terms indicates that the term 'factor' refers to a fact or situation that will contribute to a result. Hence referring to risk management, this term would denote an influence that has a bearing on the outcome of the project. In other words, without the factor it is impossible to achieve the established project objectives.

An 'indicator' is described as something that shows what a situation is like or something that indicates the level of a result. Therefore with reference to risk management, this could be certain exhibits that could be observed or measured to tell the level of improvement of risk management.

The terms 'attribute' refers to the description of a quality or characteristic that someone or something has. Consequently, with reference to risk management this would refer to the quality or the particularity of an activity.

This study sought to establish the factors of risk management. Having scrutinised the terms that have been employed in other studies, and also based on the definition of RM, which is the identification, assessment, and prioritization of risks followed by coordinated and economical application of resources to minimize, monitor, and control the 
probability and/or impact of unfortunate events [45]. Risk management can therefore be said to be composed of risk identification and assessment, risk prioritisation, and application of resources to reduce the impact of unwanted events [4]; [5].These are the aspects that can be referred to as the elements of RM generally. Reference [6] correctly refers to three of these, namely; risk assessment, risk response and monitoring as elements of risk management. From the definition, an element is a part of something. These elements in turn influence or contribute to project risk management effectiveness.

As for the terms that would refer to aspects that constitute risk management and influence project outcome, the term 'factor' is more appropriate as it denotes a fact or situation which influences the result of something.

The argument in this study is that it is much more beneficial, proactive and feasible to operationalize the concept of risk management by establishing the factors of risk management that contribute or influence performance of construction projects. Having established these then, efforts can be directed at improving and monitoring these factors. The task then is to identify these factors that are key to risk management and thus be used as influencers of project performance.

\section{Identifying factors of risk management}

This section identifies factors of RM that have been said to influence project performance without regard to the term that it was called but rather focus on its active description. The various factors that have been identified are outlined in Table 1.

In a survey conducted by reference [22] established four core RM elements influencing project success namely RM foundations, risk identification and assessment, risk measurement and reporting, and risk mitigation and management. According to the author, each of these elements should be developed and connected so as to work as an integrated whole. Each of these elements comprises of sub-elements as follows:

- The sub-elements of RM foundations were: senior management and board participation, governance structure, resource allocation, culture principles and values, risk management framework and policies, linkage to strategy, performance measurement, and organisational learning.

- The sub-elements of risk identification and assessment were: top-down assessments, Barriers to strategic and financial goals, Executive team CSAs, Bottom-up assessments, barriers to business, customer, and product goals, business unit CSAs, functional unit CSAs, Independent assessments, Internal and external audit, Regulators, Customers and other stakeholders.

- The sub-elements of risk measurement and reporting were: RM dashboard, Earnings volatility, Key risk metrics, Policy compliance, Real-time event escalation, Drill-down capabilities, Scenario analysis, Historical, Managerial, Simulation-based, Disclosure, Board reporting and External reporting.

- The sub-elements of risk mitigation and management were: policy enforcement, risk based pricing, and growth strategies, contingency planning and testing and Event and crisis management.

Reference [58] developed a framework to evaluate the effectiveness of monitoring and evaluation function in attaining project success in Kenya. They found four main factors which were referred to as the best project management practices. They include: managing communications; managing Stakeholders; motivating; and knowledge Transfer.

Reference [52] developed a framework to assist managers to manage various risks associated with their projects in Ethiopia. They found out that, personally focused cultural values, such as openness to change, rather than socially focused cultural values, such as self-transcendence was significant to project team performance. They further found that cultural values to have a strong relationship with two out of three dimensions of Project Team Success, namely, project team learning and development, as well as project team working spirit, when compared to project team leadership.

Reference [23] developed a framework to study the influence of portfolio RM on project success in Kenya. The study highlighted the interrelationship of the elements and how they impacted on the outcome of the project. The study was validated by respondents who were involved in project implementation at various levels. Four factors were measured using fourteen indicators. It was revealed that understanding the interdependencies between projects and their risks allows the manager to use synergies between projects thus the study concludes that risk management skills had a positive impact on project success in Kenya.

They established that risk management skills influence project success indirectly through risk identification, risk prevention, and risk monitoring. The four factors that influenced project outcome were: risk management skills; risk identification; risk prevention; and risk monitoring.

Reference [20] developed a framework of risk management to measure project

RM process for contractors with statement indicators linked to numerical scores. The overall project of the study 
was to ascertain the extent to which the current project RM practices are used by constructors in Malawi. They identified ten RM practices that have been discussed consistently in reports concerning RM in construction namely; risk identification; risk analysis; systems risk approach; risk exposure; risk prioritization; risk response; risk contingency planning; Risk monitoring; risk continuous assessment and the application of total quality management tools. It was found that contractors, in general, were characterised by a low implementation of the various required steps for the project RM process. They further found that most of the variables under project RM process were positively and significantly related to progression in size and experience of contractors. The study also revealed that when the risk management practices were implemented, the company achieved financial benefit in reducing lost time and employee compensation expenses.

Reference [21] developed a framework to examine the practice employed for health and safety risk assessment, communication and control at construction sites in Tanzania with a view to developing preconditions necessary to improve health and safety risk situations in construction sites. The main argument presented in the framework is that the process of risk assessment and communication is a social construction influenced by four main elements/factors that can enhance the risk management process on construction sites. These elements are the institutional system, organisational system, individual System and work environment system. Furthermore, each system had sub-elements:

- The sub-elements for institutional system were: policies/regulations and control mechanism;

- The sub-elements for organisational system were: Policies on H\&S, Management style, and resource allocations

- The sub-elements for the individual system were: Perception/altitude, Experience, Education, Power relation and trust.

- The sub-elements for work environment system were: Working tools/methods/location, Work teams, working procedure and Physical space

Likewise reference [59] developed a framework to propose the key success factors, which when implemented effectively will enhance the control procedures in an organisation. The authors pointed out that Project control mainly depends on field data for assessing, analysing and corrective actions. So, quality and quick access to field data are important. This would be best possible when the team works in co-ordination with site management. He established seven fundamental factors for project control: develop the project plan, establish the project benchmarks, monitor the project performance, identify performance deviations, Evaluate corrective options, make adjustments as needed, and document, report, and evaluate results.

However, the above factors and sub factors are too abstract and make measurement of these equally difficult as the overall RMFs. The synthesized surveys were from United Kingdom, Australia, America, South Africa, Kenya, Ethiopia, Singapore, China, and Thailand.

Table 1. Factors of risk management

\begin{tabular}{|l|l|}
\hline Factors & Source \\
\hline Organisational environment & Phoya (2012) \\
\hline Defining objectives & Papke-Shields et al. (2010) \\
\hline Resource requirement & Phoya (2012) \\
\hline Risk measurement & Oztas \& Okmen (2004) \\
\hline Risk identification & $\begin{array}{l}\text { Oztas \& Okmen (2004); Matalanga \& karanja (2014); Matalanga \& } \\
\text { karanja (2014); Papke-Shields et al. (2010) }\end{array}$ \\
\hline Risk assessment & Oztas \& Okmen (2004); Papke-Shields et al. (2010) \\
\hline Risk response \& action planning & Mahendra et al., (2013); Papke-Shields et al. (2010) \\
\hline Communication & Kamau \& Mohamed (2015) \\
\hline $\begin{array}{l}\text { Monitoring, review and continuous } \\
\text { improvement }\end{array}$ & $\begin{array}{l}\text { Matalanga \& karanja (2014); Mahendra et al. (2013); Papke- } \\
\text { Shields et al. (2010) }\end{array}$ \\
\hline
\end{tabular}

\section{Identified risk management factors and they measures}

A list of RMFs which are deemed to influence project performance has been drawn based on the above analyse. This list was drawn based on the similarity of the factors from the studies reviewed disregarding the different terms used. In addition to the factors, 43 measures were also identified and were categorised in 9 factors. The nine core factors of risk management which influence project performance include, (1) organisational environment (2) defining objectives (3) resource requirement (4) risk measurement (5) risk identification (6) risk assessment (7) risk response and action planning (8) communication and (9) monitoring, review and continuous improvement. These have been found to be common to all studies. These factors together with their measures were therefore used to propose the conceptual model of risk management. Table 2 below depicts the identified factor with their measures. 
Table 2. Measures of factors of risk management

\begin{tabular}{|c|c|}
\hline Factors & Measures \\
\hline $\begin{array}{l}\text { Organisational } \\
\text { environment }\end{array}$ & $\begin{array}{l}\text { 1.Identifies and assess the internal environmental factors } \\
\text { 2.Identifies and assess the external environment factors } \\
\text { 3.Understands the internal environment, which concerns all factors influencing the } \\
\text { manner in which firms manage risks } \\
\text { 4.Uses the organisation business system to document the internal \& external } \\
\text { environment }\end{array}$ \\
\hline Defining objectives & $\begin{array}{l}\text { 1.Defines the organisational focus } \\
\text { 2.Determine the positioning of the risk management function within the organisation } \\
\text { 3. Define the objectives and methodology of the risk management process. } \\
\text { 4. Determine how the effectiveness of the risk management process can be assessed } \\
\text { 5. Determine how the effectiveness of the risk management process can be assessed. } \\
\text { 6. Determine how the responsibility \& accountability for the risk management process } \\
\text { can be defined }\end{array}$ \\
\hline Resource requirement & $\begin{array}{l}\text { 1. Considers the personnel availability and know-how. } \\
\text { 2. Considers time requirement in terms of scheduling risk meetings/workshops. } \\
\text { 3. Considers information system requirements in identifying risks, implementing } \\
\text { controls and follow-up activities. } \\
\text { 4. Considers risk communication mechanism. }\end{array}$ \\
\hline Risk measurement & $\begin{array}{l}\text { 1.Define the risk measurement to be used } \\
\text { 2. Defines the risk materiality } \\
\text { 3.Define the risk timeframe applicable to risk impact and risk probability } \\
\text { 4. Clarify the risk terminology } \\
\text { 5. Determines the level of acceptable risk. }\end{array}$ \\
\hline Risk identification & $\begin{array}{l}\text { 1. Develop risk information database } \\
\text { 2. Conduct present and future risk identification } \\
\text { 3. Identify how and why risk arise } \\
\text { 4. Use physical inspection to identify the risk }\end{array}$ \\
\hline Risk assessment & $\begin{array}{l}\text { 1. Determine the risk cause, risk duration, risk volatility } \\
\text { 2. Determine the probability of the risk occurring, the impact, classification } \\
\text { consistency. } \\
\text { 3. Establish the risk profile. } \\
\text { 4. Assess the risk by quantitative analysis methods } \\
\text { 5. Assess the risk by qualitative analysis methods }\end{array}$ \\
\hline $\begin{array}{l}\text { Risk response and action } \\
\text { planning }\end{array}$ & $\begin{array}{l}\text { 1. Identify risk treatment options by avoiding risk } \\
\text { 2. identify risk treatment options by mitigating risk } \\
\text { 3. Identify risk treatment options by retaining risk } \\
\text { 4. Identify risk treatment options by transferring risk } \\
\text { 5.Define actions to counter the identified project risk } \\
\text { 6. Prepare an implement risk action plan }\end{array}$ \\
\hline Communication & $\begin{array}{l}\text { 1. Establish a communication process for interactive (two-way) consultation with } \\
\text { stakeholders. } \\
2 \text { Establish a reporting structure, whereby risk information derived from the risk } \\
\text { management process, is communicated timeously to appropriate parties. } \\
\text { 3. Establish a crisis communication strategy facilitating } \\
\text { immediate information exchange } \\
\text { 4. Develop a communication evaluation mechanism }\end{array}$ \\
\hline $\begin{array}{l}\text { Monitoring, review and } \\
\text { continuous improvement }\end{array}$ & $\begin{array}{l}\text { 1. Assign responsibility for monitoring and review actions. } \\
\text { 2. Identify and select monitoring and review techniques } \\
\text { 3. Assess control effectiveness, measured in terms of meeting departmental, } \\
\text { organisational objectives. } \\
\text { 4. Do control enhancement by revising ineffective } \\
\text { controls identified } \\
\text { 5. Report the new results from monitoring and review activities. }\end{array}$ \\
\hline
\end{tabular}

From the insight of the above measures it can be inferred that RM can be characterised at all levels of the organisation or industry. The insight can expose the way things are done concerning the identified factors [59]; [60]. Furthermore, it is possible to build a picture of an organisation and also understand where opportunities for improvement lie. Some researchers such as [13]; [14]; [15]; [16] proposed a plan that can be followed at organisational and industry level in order to improve RM effectiveness as follows:(1) Assessing the organisation current level of RM (2) Developing a plan to move to the next level (3) Implement the plan (4) Monitor the implementation of the plan (5) Re-assess the level of RM for further actions.

It is easier and practical to view the identified factors of 1) organisational environment (2) defining objectives (3) resource requirement (4) risk measurement (5) risk identification (6) risk assessment (7) risk response and action planning (8) communication and (9) monitoring, review and continuous improvement that can be used to improve 
RM effectiveness. The process of improvement can therefore follow the following stages: (1) Assess the model (2) Develop methods to enhance the model (3) Implement methods (4) Assess the model (5) Compare with baseline levels to indicate movement (6) Consult and disseminate information (7) Develop methods to enhance the model and (8) Repeat process 3-8.

It is importance to note that implementing the model has to take cognisance of the external environment factors that can similarly have an influence on project performance. This statement was supported by [21] who indicated that RM at organisation level does not operate in a vacuum; rather it affects and is affected by the external environment.

\section{Methodology}

The work methodology included a literature search. The study was conducted with reference to preceding literature to risk management. This is because RM has attracted much worldwide attention in recent years [40]. The literature search was based on systematic keyword combination search online databases and by consulting Journals and conference proceedings. Database engines search included; Science Direct, Taylor and Francis Online, Ebscohost, and Emerald. The authors used advanced search for the database engines and basic search for Google. The keywords and phrases used for the data search were;" risk management", "risk management influence on project outcome in construction", and "risk management effectiveness measures". The basic search used was "factors of risk management in construction". Articles/reports consulted were peer-reviewed articles, written in English, they indicated the objective of the study; the method employed, and report the results to the objective of this literature and a conclusion.

\section{Discussion and conclusion}

This study sought to identify RMFs that are indispensable to make the notion valuable in the CI. The reason why RM should be taken into consideration in the CI has been outlined. It was further noticed that RM effectiveness improvement is improbable without the improvement or change in the way risk is approached.

The factors of risk management were identified. It was observed that the reason RMFs has not been employed to the full has been undoubtedly to the various terms that have been utilised to characterise RM and consequently the resultant confusion. It was also revealed that it is beneficial to consider those factors that influence project performance and subsequently measure their metrics. This has been said to be more proactive and practical.

The core RMFs that were revealed to be common in literature included organisational environment, defining objectives, resource requirement, risk measurement, risk identification, risk assessment, risk response and action planning, communication, monitoring, review and continuous improvement which have collectively been referred to as RMFs for project performance improvement.

It was further evinced that the identified factors can be employed to both plan for and measure RM effectiveness. The present study has thus contributed to the efforts aimed at improving RM effectiveness in the CI by demonstrating how RM can be operationalized practically.

\section{References}

[1] OECD Insights (2016). The Global Construction Sector Needs a Big Push on Corporate Responsibility, available from: http://oecdinsights.org/2016/08/22/global-construction-sector-corporate-responsibility/. Accessed: 26/02/2018

[2] C.G. Martins. (2006). Aplicação das Técnicas de Identificação de Risco em Projetos de E and P. 2006. 93f. Monografia (Pós-Graduação-MBA em Engenharia Econômica eFinanceira)-Universidade Federal Fluminense -UFF. Niterói.

[3] COSO (2004). Enterprise Risk Management - Integrated Framework: Executive Summary \& Framework, Committee of Sponsoring Organizations of the Tread Way Commission, Jersey City, NJ

[4] A.P. Liebenberg, R.E. Hoyt. (2003). The determinants of enterprise risk management: evidence from the appointment of chief risk officers, Risk Management and Insurance Review, 6 (1):37-52.

[5] I.O. Olamiwale. (2014). Evaluation of risk management practices in the construction industry in Swaziland, Master's Thesis, Tshwane University of Technology, Pretoria, South Africa.

[6] L.D. Nguyen, S.O. Ogunlana, D.T.X. Lan. (2004). A study on project success factors in large construction projects in Vietnam, Engineering, Construction and Architectural Management, 11(6): 404-413.

[7] I. Beleiu, E Crisan, R Nistor. (2015). Main factors influencing project success, Interdisciplinary Management Research, 11:59-72.

[8] B. Weinstein, K. Blacker, R. Mills. (2003). Risk management for nonexecutive directors:

[9] X. Zhao, B.G. Hwang, S.P. Low. (2015). Enterprise risk management in international construction firms: drivers and hindrances, Engineering, Construction and Architectural Management, 22 (3):347-366.

[10] M. Beasley, A. Chen, K. Nunez, L. Wright. (2010). Working Hand in Hand: Balanced Scorecard and Enterprise Risk Management, Strategic Finance, March: 49-55. 
[11] A.E. Kleffner, R.B. Lee, B. McGannon. (2003). The Effect of Corporate Governance on the Use of Enterprise Risk Management: Evidence from Canada. Risk Management \& Insurance Review, 6(1):53-73.

[12] D. Wu, D.L. Olson. (2009). Enterprise risk management: small business scorecard analysis, Production Planning \& Control, 20 (4):362-369.

[13] D.P. Pagach, R.S. Warr. (2011). The characteristics of firms that hire chief risk officers, Journal of Risk and Insurance, 78 (1):185-211.

[14] B.W. Nocco, R.M. Stulz. (2006). Enterprise risks management: theory and practice, Journal of Applied Corporate Finance, 18 (4):8-20.

[15] J.S Chou, J.G Yang. (2012). Project management knowledge and effects on construction project outcomes: an empirical study, Project Management Journal, 43 (5): 47-67.

[16] KPMG (2010). Charting a Safe and Sustainable Growth Journey: Singapore Enterprise Risk Management Survey 2010, KPMG in Singapore, Singapore.

[17] J.Y. Liu, S.P. Low, X. He. (2011). Current practices and challenges of implementing enterprise risk management (ERM) in Chinese construction enterprises, International Journal of Construction Management, 11 (4):49-63.

[18] K. Muralidhar. (2010). Enterprise risk management in the Middle East oil industry: an empirical investigation across GCC countries, International Journal of Energy Sector Management, 4 (1):59-86.

[19] K. Narvaez. (2011). Success Stories: Public Entities Adopt ERM Best Practices, Public Entity Risk Institute, Fairfax, VA.

[20] K. E. Papke-Shields, C. Beise, J. Quan. (2010). Do project managers practice what they preach, and does it matter to project success? International Journal of Project Management, 28(7), 650-662.

[21] S. Phoya (2012). Health and Safety Risk Management in Building Construction Sites in Tanzania: The Practice of Risk Assessment and Control'. Thesis for the Degree of Licentiate of Engineering, Chalmers University of Technology, Gothenburg, Sweden.

[22] A. Oztas, O. Okmen. (2004). Risk analysis in fixed price design-build construction Industry, International Journal of Project Management, 26 (4): 431-438.

[23] O.E. Matalanga, N.P. Kranja. (2014). Influence of Portfolio risk management on project success among commercial Bank in Kenya, International Journal of Social Sciences Management and Entrepreneurship, 1(3): 57-75.

[24] S. Shunmugam P.D. Rwelamila. (2014). An evaluation of the status of risk management in South African construction projects, Proceedings of the Project Management South Africa (PMSA) Conference, ISBN: 978-0-620-64562-1 29, 30 September and 1 October, Johannesburg, South Africa.

[25] South African Politics. (2013). South African Politics. (Online). Available from http://www.sapolitics.co.za/157/remaining-gautrainconstruction-claims-likely-to-go-to-arbitration, [Accessed: 09/02/2018]

[26] S. Guern Le. (2013). First fuel begins to flow through SA's new R23bn fuel pipeline. (Online) Available from http://www.engineeringnews.co.za/article/new-multi-product-pipeline-2013-01-18, [Accessed: 09/02/2018].

[27] R. Funston. (2003). Creating a Risk-intelligent Organization, Internal Auditor, 60(2):59-63.

[28] Taroun, A. (2012). Towards a better modelling and assessment for construction risk: Insights from a literature review, International Journal of project Management, 32(1):101-115

[29] S. Chihuri, L. Pretorious. (2010). Managing risks for Success in a South African Engineering and Construction Project Environment, South African Journal of Industrial Engineering, 21(2):63-77.

[30] M. Prince. (2000). Enterprise risk management: RMIS requires corporate cultural transformation. Business Insurance, 34(49):21-23.

[31] Rounds, J. \& Segner, R.O. (2011). Construction supervision, completion, risk, and construction company failure, John Wiley and Sons, Hoboken, NJ, P171.

[32] W. Imbeah, S. Guikema. (2009). Managing construction projects using the advance programmatic risk analysis and management model, Journal of Construction Engineering and Management, 135(8): 772-781.

[33] L.M. Gitau. (2015). The effects of risk management at project planning phase on performance of construction projects in Rwanda, Master's thesis, Jomo Kenyatta University of Agriculture And Technology, Rwanda.

[34] N. M. El-Gohary, H. Osman, T. E. Ei-Diraby. (2006). Stakeholder management for public-private partnerships, International Journal of Project Management, 24(7):595-604.

[35] L. Bosher, A. Dainty, P. Carrillo, J Glass, A. Price. (2007). Integrating disaster risk management into construction: a UK perspective, Journal of Building Research \& Information, 35(2):163- 177.

[36] N.L. Nielson, A.E. Kleffner, R.B. Lee. (2005). The evolution of the role of risk communication in effective risk management", Risk Management and Insurance Review, 8(2):279-289

[37] J. Bologa. (2003). Focus on Risk Management. Internal Auditor, 60(4):9.

[38] Chapman, C. (2003). Bringing ERM into Focus. Internal Auditor, 60(3):30-35.

[39] R. Levine. (2004). Risk Management Systems: Understanding the need, Information Systems Management, 21(2):31-37.

[40] A. Klemetti. (2006). Risk management in construction project networks. Laboratory of Industrial Management, Helsinki University of Technology.

[41] D. Haughey. (2014). Eight Key Factors to Ensuring Project Success. Available from https://www.projectsmart.co.uk/white-papers/eight-keyfactors-to-ensuring-projectsuccess.pdf [accessed: 12/03/2016]

[42] D. McGeorge, P.X.W. Zou. (2013). Construction Management: New Directions, Willey-Blackwell, Chichester.

[43] A.F. Gildberg, B. Elverdam, I. Hounsgaard. (2010). Forensic psychiatric nursing: A literature review and thematic analysis of staff patient Intereaction, Journal of Psychiatric and metal Health Nursing, 17: 359-368.

[44] S. Aimable. (2015). Effects of risk management methods on project performance in Rwandan construction industry: A case study of the multistorey buildings construction project of RSSB, Master thesis, University of Agriculture, and Technology (Kigali Campus), Rwanda.

[45] D.K. Truslow, (2003). Operational Risk Management: It's Everyone's Job, The RMA Journal, 85(5):34-37.

[46] P. Nakada, C. Tange (2003). The Risk Management of War versus Decentralized Control, The RMA Journal, 85(6):30-31.

[47] W. Smiechewicz. (2001). Case Study: Implementing Enterprise Risk Management. Bank Accounting \& Finance, 14(4):21-27.

[48] J.W. DeLoach. (2000). Enterprise-Wide Risk Management. Strategies for linking risk and opportunity. London: Financial Times Prentice Hall.

[49] O. Zwikael, (2009). Critical planning processes in construction projects, Construction Innovation, 9(4):372-387. 
[50] R.J. Chapman. (2001). The controlling influences on effective risk identification and assessment for construction design management. International Journal of Project Management, 19(3):147-160.

[51] P.W. Schrøder. (2006). Impediments to Effective Risk Management. Perspectives on Strategic Risk Management. [In: Andersen, T.J. (Ed.). Perspectives on Strategic Risk Management. Denmark: Copenhagen Business School Press].

[52] P. Kishan, R. Bhatt, Bhavsar. (2014). A study of risk factors affecting building construction projects, International Journal of Engineering research and Technology, 3(12):831-835

[53] D. Myers. (2013). Construction Economics: A new approach $3^{\text {rd }}$ Edition. New York: Routledge

[54] S. Segal. (2011), Corporate Value of Enterprise Risk Management, John Wiley \& Sons, Hoboken, NJ.

[55] M. Jablonowski. (2001). Thinking in numbers, Risk Management, 48 (2):30-35.

[56] Z/NZS ISO 31000:2009. Risk Management. Standards Australia International Ltd, Sydney.

[57] N.A Manab, I. Kassim, M.R. Hussin. (2010). Enterprise-wide risk management (EWRM) practices: between corporate governance compliance and value creation, International Review of Business Research Papers, 6 (2):239-252.

[58] C.G. Kamau, H.G. Mohamed. (2015). The efficacy of monitoring and evaluation function in achieving project success in Kenya, Science Journal of business and Management, 3(3):82-94

[59] P.A. Mahendra, J.R. Pitroda, J.J. Bhavsar. (2013). A study of risk management techniques for construction projects in developing countries, International Journal of Innovation Technology and Exploring Enginnering, 3(5):139-142.

[60] L.A. Gordon, M.P. Loeb, C.Y. Tseng. (2009). Enterprise risk management and firm performance: a contingency perspective, Journal of Accounting and Public Policy, 28(4):301-327. 